\title{
High Efficiency DC/DC Boost Converters for Medium/High Power Applications
}

\author{
Furqan Zahoor*, Swastik Gupta and Vipan Kakkar \\ Department of Electronics and Communication Engineering, Shri Mata Vaishno \\ Devi University, India \\ *14mmc011@smvdu.ac.in,swastik.gupta@smvdu.ac.in, \\ vipan.kakar@smvdu.ac.in
}

\begin{abstract}
Switching Converters commonly known as DC/DC Converters have gained tremendous popularity due to their use in variety of applications such as hybrid energy ystems, hybrid vehicles, satellite applications and portable electronic devices to name a few. The main positives of using high step up converters include improving voltage gain, reduction of voltage stress and current ripple. But these converters seem to have some disadvantages like very high EMI due to reverse recovery of the boost diode and considerable amount of losses which occur due to hord switching of the boost switch. Many variations of the original boost schematic have been suggested to overcome these problems. The Zero Voltage Transition (ZVT) Boost Conyerter and Zero Current Transition (ZCT) Boost converter are such solutions. These soft switching topologies employ an auxiliary resonant circuit which allows the boost switch to turn on and off under zero voltage and zero current conditions respectively thus reducing the switching losses. In addition, these boost converter circuit have major drawback of low power efficiency particularly at light loads due to the negative value of inductor current at light loads. In this research, a novet technique for designing a boost converter is proposed. The proposed converter mploys an auxiliary circuit which allows switching of the main switch as well as the ausitiary switch ander zero voltage/zero current conditions. In addition, the boost converter automatically senses the zero current across the resonant inductor, thus foraing the convertor to step automatically from Continuous Conduction Mode (CCM) Discontinyous conduction mode (DCM) when the inductor current tries to go negative. This prevents the inductor current to go negative and hence improve convertor's power efficiency. A novel boost convertor which steps up $200 \mathrm{~V}$ input voltage to $400 \mathrm{~V}$ output is designed in PSIM software with a switching frequency of $100 \mathrm{KHz}$. The simulation result show that the proposed convertor has an efficiency of about $99.3 \%$ at nominal output power.
\end{abstract}

Keywords. Boost Converter, DC/DC convertor, Power efficiency of Boost convertor, Swithing Mode Power Supply, Zero Current Switching (ZCS), Zero Voltage Switching

\section{Introduction}

Switching converters commonly known as the DC/DC Converters with Pulse Width Modulation (PWM) are widely used circuits in many industrial applications. They convert a fixed-voltage dc source into a variable-voltage dc source. DC/DC Converters are usually used to obtain an output voltage which is: i) higher in magnitude (Boost) than the input voltage or ii) lower in magnitude (Buck) than the input voltage or iii) Both higher and lower (Buck Boost) than the input voltage. This literature is related only with the DC/DC Boost Convertors. When Boost, converters are operated at high frequencies, they suffer 
significant reverse recovery related losses which become more prominent when the converter is switched under hard switching conditions. Therefore, the Boost Converters need to be operated at low switching frequencies to achieve higher conversion efficiencies. Thus, by introducing the concept of soft switching, will significantly enhance the switching frequency and therefore the power density of the Boost Converters.

Till date, a significant number of soft switched boost converters have been proposed [1] - [11]. To control the turn-off di/dt rate of the rectifier, Soft switching converters employ various additional components such as inductor and capacitor thus forming a snubber circuit. By implementing various soft switching techniques, the switch will make a transition from its on-state to its off state and from its off state to its on state at the instant when the switch voltage or the switch current is zero. This will prevent the occurrence of the switching losses. Soft Switching techniques are mainly categorized as: i) Zero Voltage Switching (ZVS) and ii) Zero Current Switching (ZCS). During switching period when either voltage or current is zero, then the product of voltage and current becomes zero which in turn means that there is ideally no power loss in the device. Thus, Soft Switching results in enhanced system efficiency.

In [1], [2], [9], [10], [11] and [13] a concept of Zero Voltage Switching (ZNS) and Zero Current Switching (ZCS) is introduced which results in significant improvement in switching losses in the boost converter thus enhancing the efficiency/Zero Voltage Switching is presented to achieve a Zero Voltage Switching of actiye switches. This technique turns the power MOSFET switch in the Boost conventer ON \& OFF only when the drain to source voltage across it is zero. Thus, significantly reducing the power losses. On the other hand, zero current switching(ZCS) ensures that the switching takes place only at zero current.

In [8], [9], [10] a new class of Boosteconverters referred to as Novel ZVT-ZCT-PWM Boost converters were introduced with a nev kind of an active snubber cell. This approach is effective in reducing the switching losses as it mainly focusses to modify the control technique used in the earlier ZCT-PWM converter [1]. In the novel ZVT-ZCT Boost converter [11], ZVT turn on and ZCT uurn "off" of the main switch is ensured. The main devices are subjected to minimad voltage as well as minimal current stresses. In addition, the stresses on the auxiliary devices are very low in the proposed new converter. This novel ZVT-ZCT structure has an advantage of providing desirable results at light load conditions as well as at very high frequencies. The simplicity of the structure as well as minimun cost of the overall structure are the additional benefits of this soft switching topology.

In this paper, a novel technique for designing a boost converter is proposed. The proposed converter employs an auxiliary circuit which allows switching of the main switch as well as the auxiliary switch under zero voltage/zero current conditions. In addition, the boost converter automatically senses the zero current across the resonant inductor, thus forcing the convertor to step automatically from Continuous Conduction Mode (CCM) to Discontinuous conduction mode (DCM) when the inductor current tries to go negative. This prevents the inductor current to go negative and hence improve convertor's power efficiency. By using this approach, the converter achieves high efficiency over a wide load range. The results obtained from the design confirm the superior performance of the proposed converter.

\section{Proposed Architecture of Boost Converter}

The block diagram of the proposed ZCT-PWM Boost Converter is shown in Figure (1). The proposed converter is a boost converter with an auxiliary circuit, that consists of a switch (S2), a diode (Daux) placed in series with the switch "S2", a resonant capacitor $(\mathrm{Cr})$ and a resonant inductor ( $\mathrm{Lr})$. The circuit consists of various additional blocks such as: i) an error amplifier. ii) Pulse Width Modulator) 
Zero Current Detector and IV) logic block. The addition of series diode Daux in the auxiliary circuit of the ZCT PWM Boost converter has the advantage of preventing the conduction of body diode of the auxiliary switch "S2" which is a slow recovery diode. This also has the benefit of preventing the parasitic capacitance of the switch "S2" from resonating with the resonant inductor "Lr".

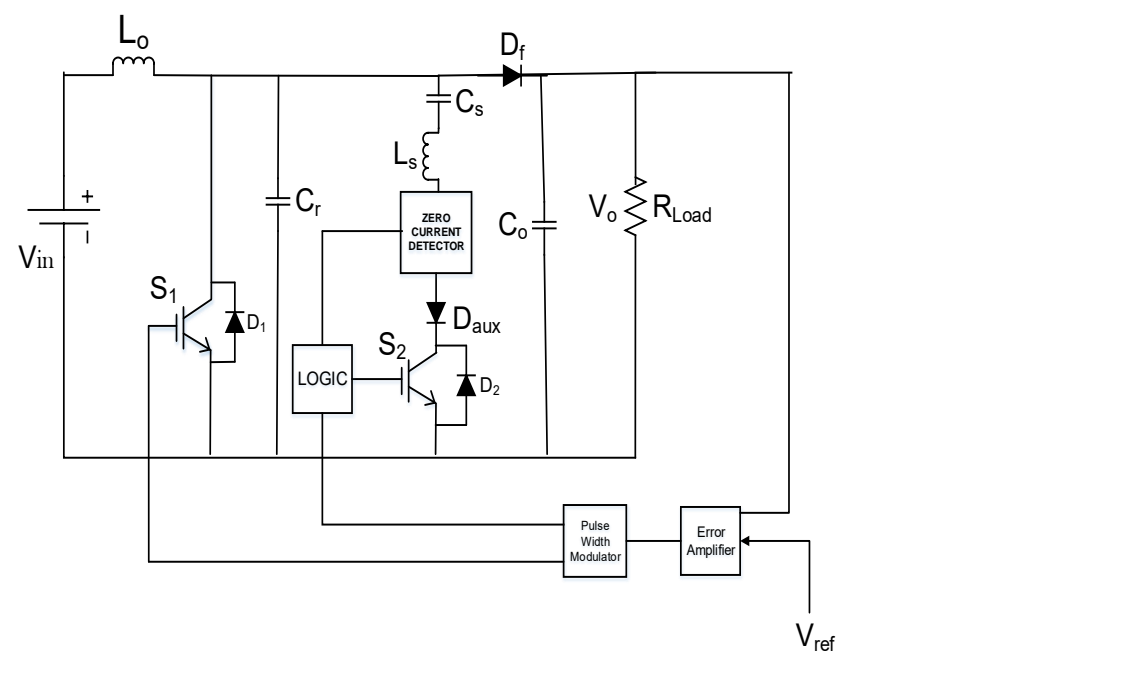

Figure 1. Block Diagram of Proposed Architecture or Boost Converter

The purpose of these various blocks in the design is mentioned as follows: The error amplifier block in the proposed ZCT-PWM boost con erter is used to compare the actual output voltage obtained from the boost topology with the desired or reference output voltage. It then produces an êrrol ignal based on the difference between these two voltages. This error voltage from the error amplifier is then fed to the next block in the topology which is the Pulse Width Modulator block. The purpose of the PWM block is to produce a pulse width modilated signal This PWM signal is applied as gate drive to the switch "S1" in the proposed ZCT PWM Boost Topology. The zero-current detector circuit is incorporated into the design to overcome the effects of negative current flow through the resonant inductor. This negative current flows due to the resonant circuit formed by the inductor and total capacitance from auxiliary switch node to ground including the parasitic capaeitance of the switch which leads to ringing's (undesirable voltage spike), thus producing noise at the output. This undesirable noise reduces the efficiency of the boost converter circuits because of the increased conduction losses due to the negative nductor current flow in the circuit. Zero current detector circuit present in the design overcomes this negative current flow problem thus enhancing the efficiency. As the current through the inductor tries to go below zero, the zero-current detector produce a control signal indicating the inductor current is zero. At this instant, we need to tun the auxiliary switch "S2" off, thus preventing the flow of negative inductor current in the circuit. The switch "S2" will be turned "off" with the help of a suitable logic block which will also take into consideration the PWM signal driving the main switch "S1".

How we can detect the zero current and what kind of logic we need to use will be discussed once we step over to the design process.

\section{Proposed Boost Converter Circuit Design}

The circuit diagram of the proposed Boost convertor designed in PSIM software is shown in the figure (2). The convertor uses PWM technique for regulating the output voltage. In addition, As the ESR of output inductor and capacitor is very low, so it uses Type III compensation technique to ensure the stability of the feedback 
loop [16], it must be noted that in the proposed Boost converter topology both the main switch as well as the auxiliary switch are chosen as Insulated Gate Bipolar Transistor (IGBT). The IGBT is a minority carrier device with a voltage drop across its collector and emitter nearly independent of the current it conducts. This is totally in contrast to the MOSFET, which acts as an equivalent drain source resistance when it conducts current.

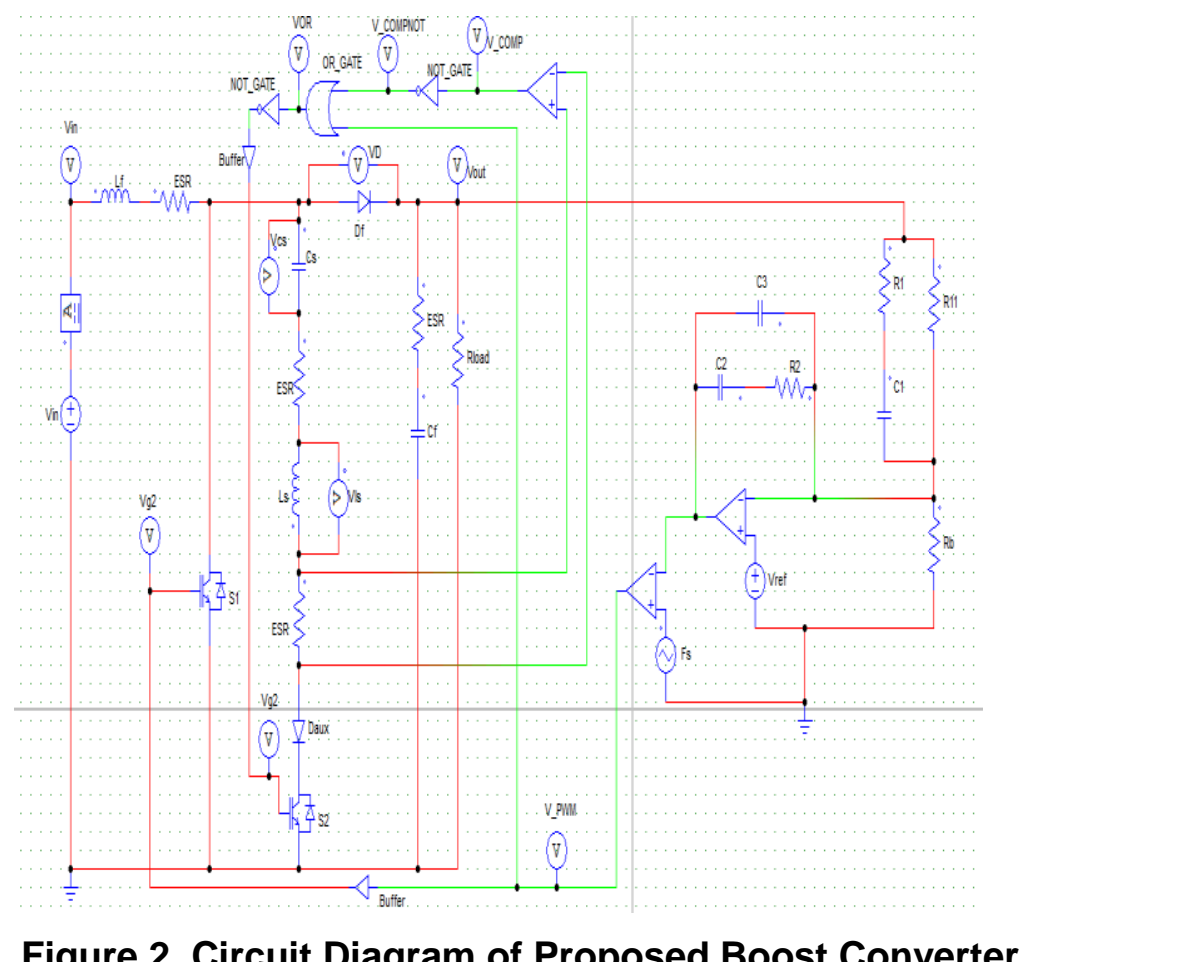

Figure 2. Circunt Diagram of Proposed Boost Converter

The nearly fixed voltage drop of the MGBT along with its higher voltage rating and power density makes it a device of choice in power applications where switches must conduct greater garrents and conduction losses can be reduced. To simplify the analysis, all the semiconductor devices and resonant circuits are assumed ideal. The switching frequency here aken is $100 \mathrm{~K} \mathrm{~Hz}$ to reduce the component size i.e. to reduce the size of output inductor and capaci or. The higher frequency results in on-chip integration of both inductor and capacitor however it also results in more switching losses in the switch transistors (IGBT). So, we take the optimum switching frequency value as $100 \mathrm{KHz}$. The design specifications of the boost convertor to be designed are given in Table I.

The boost inductor \& boost capacitance value calculation is first step in the designing process of a boost convertor. The min. value of inductor is computed by using below equations. The minimum value of inductor which ensures operation in CCM is given by [1]]

$$
\mathrm{L}_{\min }=\frac{(1-D)^{2} * D * R}{2 f} \ldots \ldots
$$

Based on the specification given in Table (I), we get the value of $L_{\min }=6.25 \mu \mathrm{H}$

The minimum value of capacitor which ensures operation in CCM is given by [17]

$$
\mathrm{C}_{\min }=\frac{D V_{0}}{V \nabla R f} \ldots \ldots
$$

Here $\mathrm{Vo} / \mathrm{Vr}=1 \%$ i.e. $\mathrm{Vr}=0.01 * \mathrm{Vo}$ and taking into consideration the specification given in Table (1), we get the value of $\mathrm{C}_{\min }=50 \mathrm{Mf}$ 
Thus, it is clear from the above equation that the capacitor size can be reduced by choosing higher switching frequency. The component values used in type III compensation network [16], in the feedback controller are given in Table II.

Table 1. Design Specifications of Boost Converter

\begin{tabular}{|l|l|}
\hline Input Voltage & $200 \mathrm{~V}$ \\
\hline Output Voltage & $400 \mathrm{~V}$ \\
\hline Switching Frequency & $100 \mathrm{Khz}$ \\
\hline Inductor ESR & $1 \mathrm{n} \Omega$ \\
\hline Capacitor ESR & $1 \mathrm{n} \Omega$ \\
\hline
\end{tabular}

Table 2. Component Values in Type II Compensator

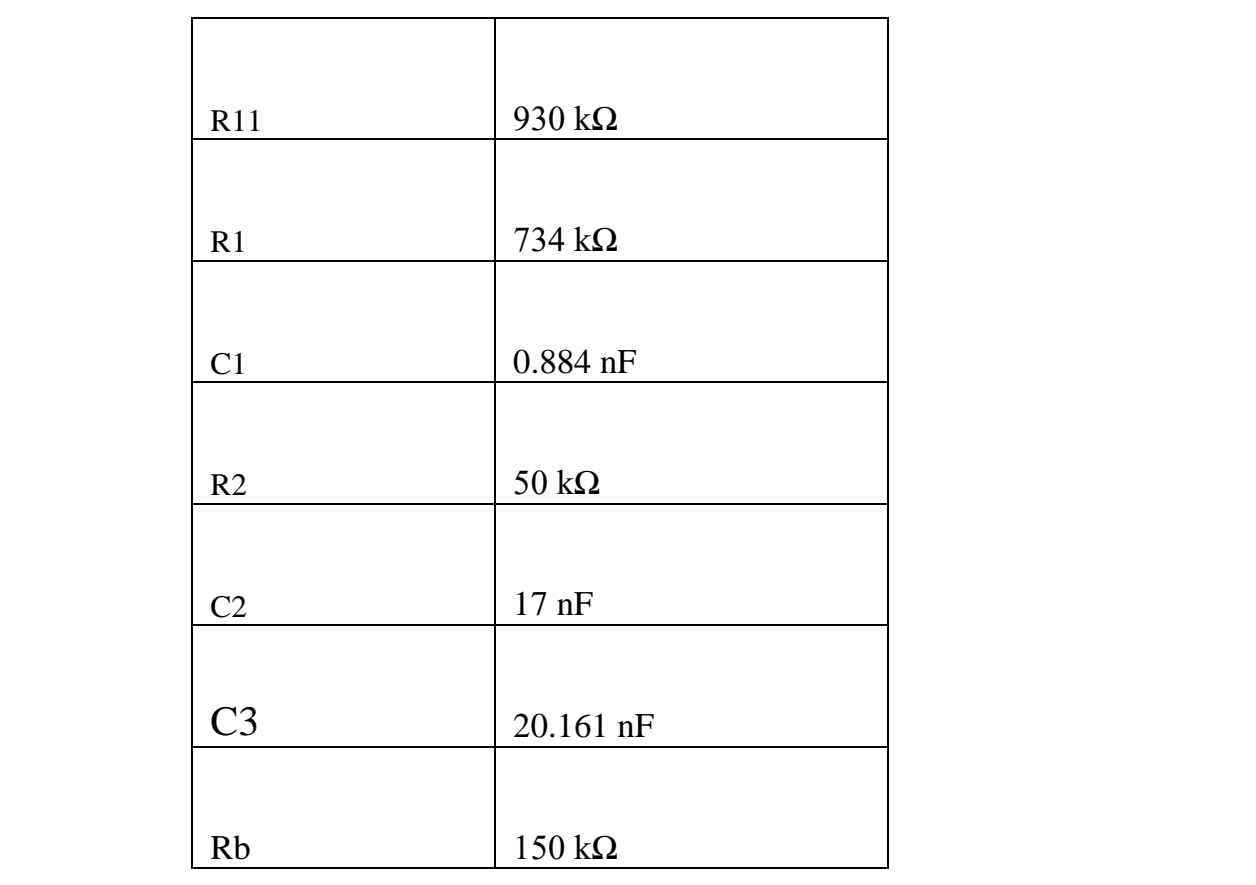

In the proposed boost converter circuit, the diode "Daux" is used to block the slow body diode of the switch "S2" from conduction. The value of resonant inductor "Lr" and resonan capacitor " $\mathrm{Cr}$ " are selected as $8 \mu \mathrm{F}$ and $8.2 \mathrm{nf}$ respectively. In addition, the reference voltage of the error amplifier $V_{\text {ref }}$ has been assigned a fixed value of $400 \mathrm{~V}$ whereas the switching frequency of the PWM block has been assigned a value of 100 KHz.

The converter operation can be described as follows: Initially prior to the time $\mathrm{t}=\mathrm{T} 0$, the input current lin is flowing through the diode Df as both the switches (S1 and S2) are in the "OFF" state.

At $\mathbf{t}=$ T0 (Mode 1), the auxiliary switch (S2) turns "ON", due to which a resonance starts between the inductor(Ls) and capacitor(Cs). Therefore, the current through the auxiliary circuit increases whereas the current through diode (Df) falls simultaneously. As a result, the diode (Df) turns off with Zero Current Switching (ZCS) conditions.

At $\mathbf{t}=\mathbf{T 1}$ (Mode 2), the capacitor "Cr" discharges due to the previously started resonance, this forces the body diode "D1" to turn on with ZVS. 
At $\mathbf{t}=\mathbf{T 2}$ (Mode 3), the main switch ( $\mathrm{S} 1$ ) is turned "ON" with ZVS and as such the current through the main switch "S1" continues to increases.

At $\mathbf{t}=\mathbf{T 3}$ (Mode 4), the current through the switch "S2" becomes zero and as such switch "S2" is turned "OFF" with ZCS.

At $\mathbf{t}=\mathbf{T} 4$ (Mode 5), as the current through the switch "S2" goes zero, the diode "Daux" connected in series with auxiliary switch(S2) prevents the conduction of the body diode (D2) of the switch "S2" which is a slow recovery diode.

At t=T5 (Mode 6), the main switch "S1" continues to conduct the input current. The switch "S1" can be turned "OFF" at some time when the current flowing through it reaches its peak value and at that instant the switch "S2" can be turned ON. Thus, the current which flows through the main switch(S1) reduces.

At $\mathbf{t}=$ T6 (Mode7), the current through the main transistor falls to zero and this turns "ON" the body diode of the main switch(S1) with ZCS. Also, the control signal of the auxiliary switch(S2) is removed.

At $\mathbf{t}=$ T7 (Mode8), the capacitor "Cr" is charged linearly under the input current. The main diode (Df) turns "ON" with ZVS and this mode finishes. This completes one switching cycle and another switching cycle starts.

Now let us understand how this converter works. Consider the waveforns shown in the Figure (3).

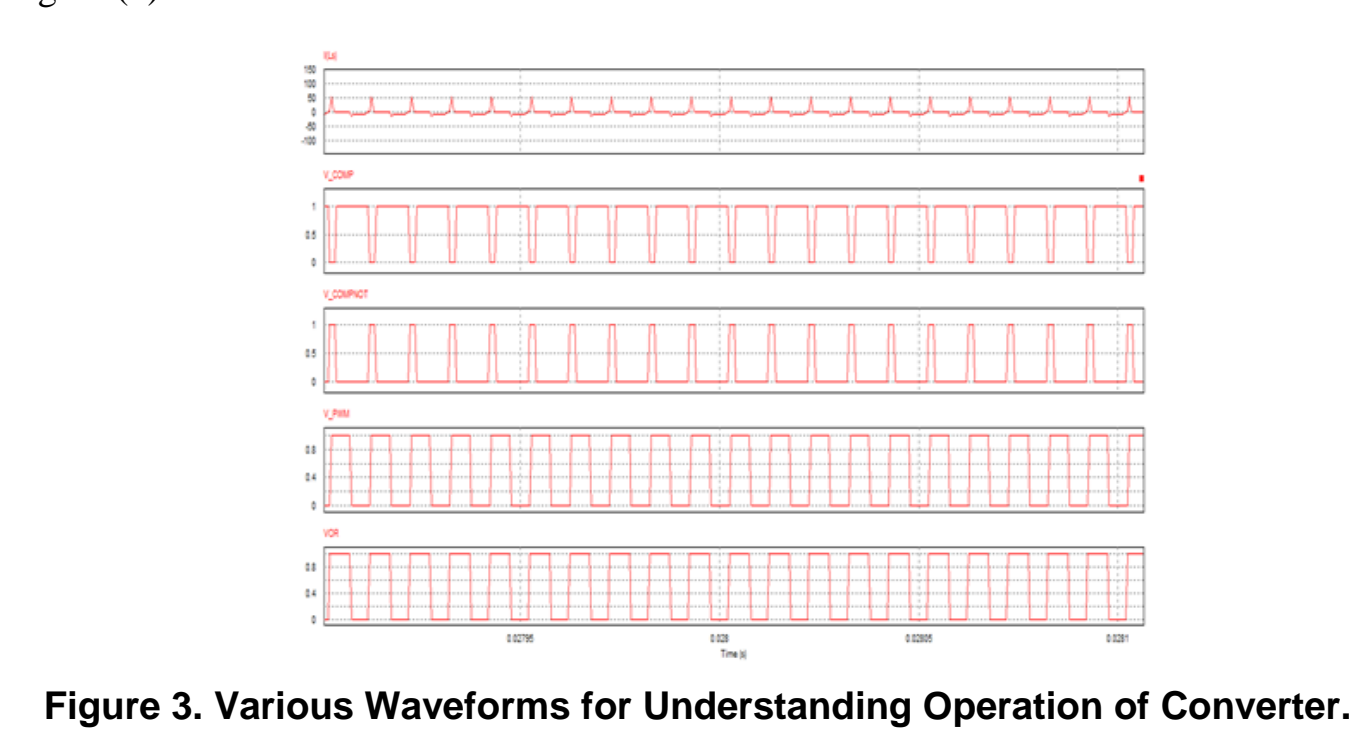

The comparatorused in circuit diagram shown in Figure (2) produces the positive pulse when the current through the resonant inductor becomes zero and it gives an output of zero when the current flowing through the resonant inductor is non-zero as clearly shown in the simulated waveforms in Figure (3). From Figure 3, if the inductor current is nonzero (positive), the output of the comparator is zero. Once the inductor current goes zero, the oomparator produces a positive pulse at the output as shown in Figure 3. The output of the comparator is represented by V_COMP whereas V_COMPNOT represents the inverted output of the comparator as shown in figure (3). When the COMP_NOT and PWM waveforms are ORed, we get the waveform presented by OR in the Figure 3. This OR waveform is again fed to the not gate to obtain a suitable logic. This signal which is obtained is fed to the auxiliary switch "S2" of the boost converter through a switch controller whereas the PWM signal is fed to main switch "S1" of the convertor. It is evident from Figure 3, as the PWM goes low, the switch "S1" of the converter is turned OFF however at this time switch "S2" of the proposed converter is turned ON as the OR waveform also is low. When PWM is high, the switch " $\mathrm{S} 1$ " is $\mathrm{ON}$. At the same time OR waveform also is high, so the switch "S2" is OFF during this period. So, the inductor current decreases linearly. Thus, as the current which flows through the resonant inductor 
falls to zero and, the output of the OR gate goes high, thus turning the switch "S2" OFF. This turning OFF the switch "S2" makes the resonant inductor current zero and prevents the flow of negative inductor current in the circuit. Thus, by making use of the PWM controller and with the help of a suitable zero current detector we obtain the control of both the auxiliary and the main switch of the proposed converter.

\section{Results of the Proposed Boost Converter}

Figure (4) shows the input and output voltage waveform of the proposed boost convertor. It is clear from the figure that the convertor steps UP the input voltage of $200 \mathrm{~V}$ to the output of $400 \mathrm{~V}$.Figure (5) shows the output current waveform under steady state for the proposed boost convertor. The output current is drawn at a load of $40 \mathrm{~A}$ i.e. when the convertor is being operated under heavy load conditions. Figure (6) shows the steady state output current waveform at a load of $0.80 \mathrm{~A}$ for the proposed boost convertor. It must be, noted that there is always flow of power from source to the load both under heayy load as well as the light load conditions. So, the efficiency of the proposed boost converter in both the cases is improved which is confirmed once we see the efficiency results at various loads. Figure (7) shows the gate control signals G1 and G2 of the switches S1 and S2 respectively.

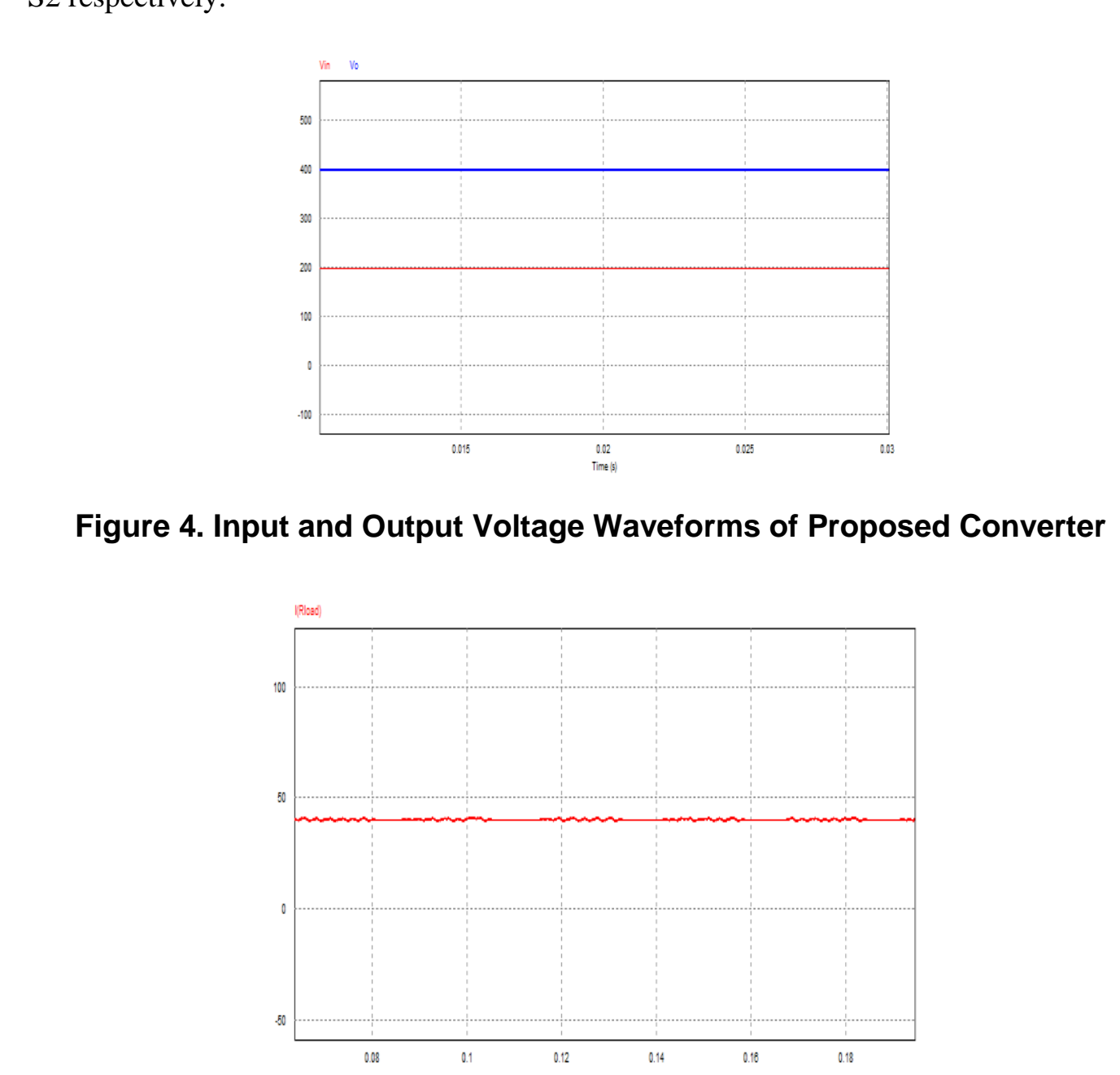

Figure 5. Output Current Waveform under Heavy Load $(\mathrm{Io}=40 \mathrm{~A})$ 


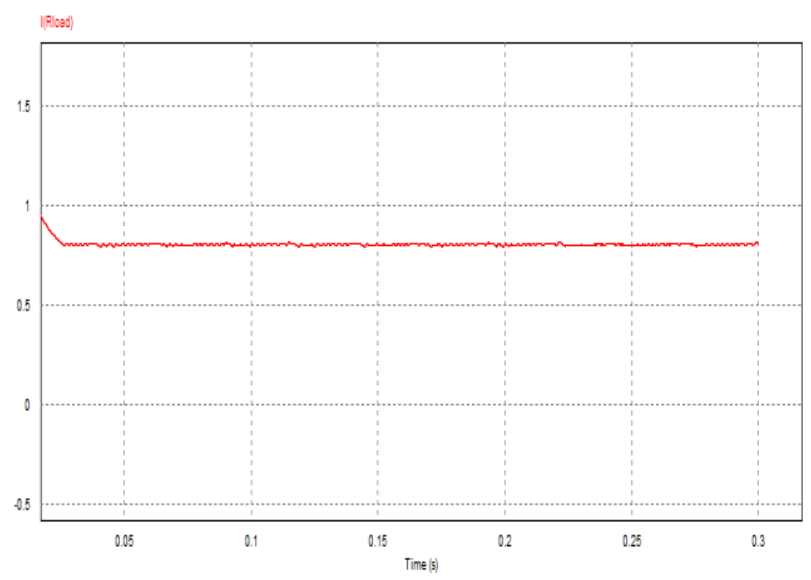

Figure 6. Output Current Waveform under Light Load (lo $=0.8 \mathrm{~A})$

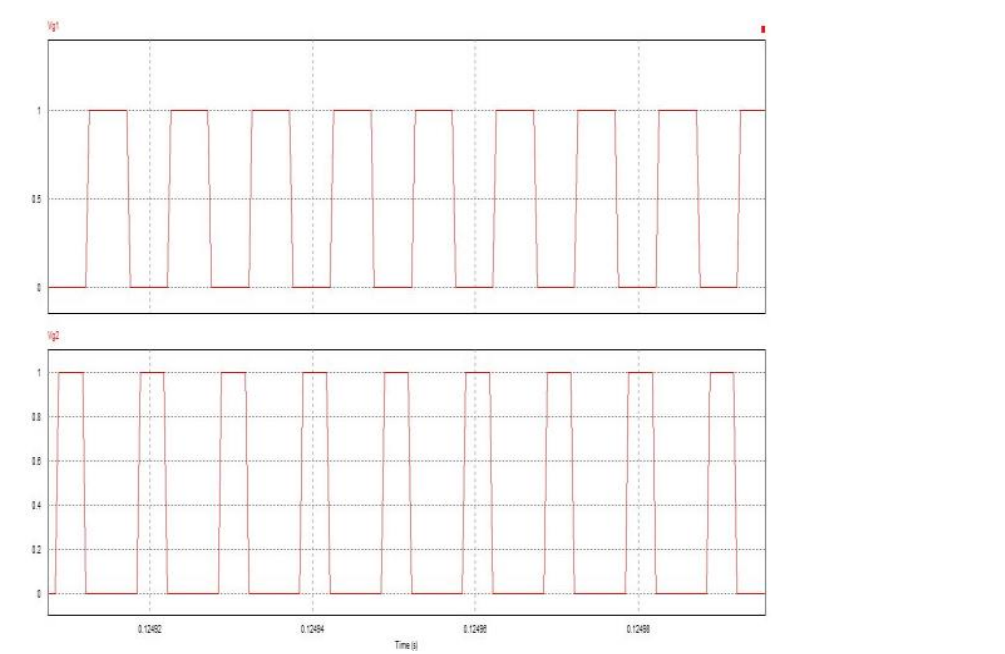

Figure 7. Cate Control Waveform of the switches S1 and S2

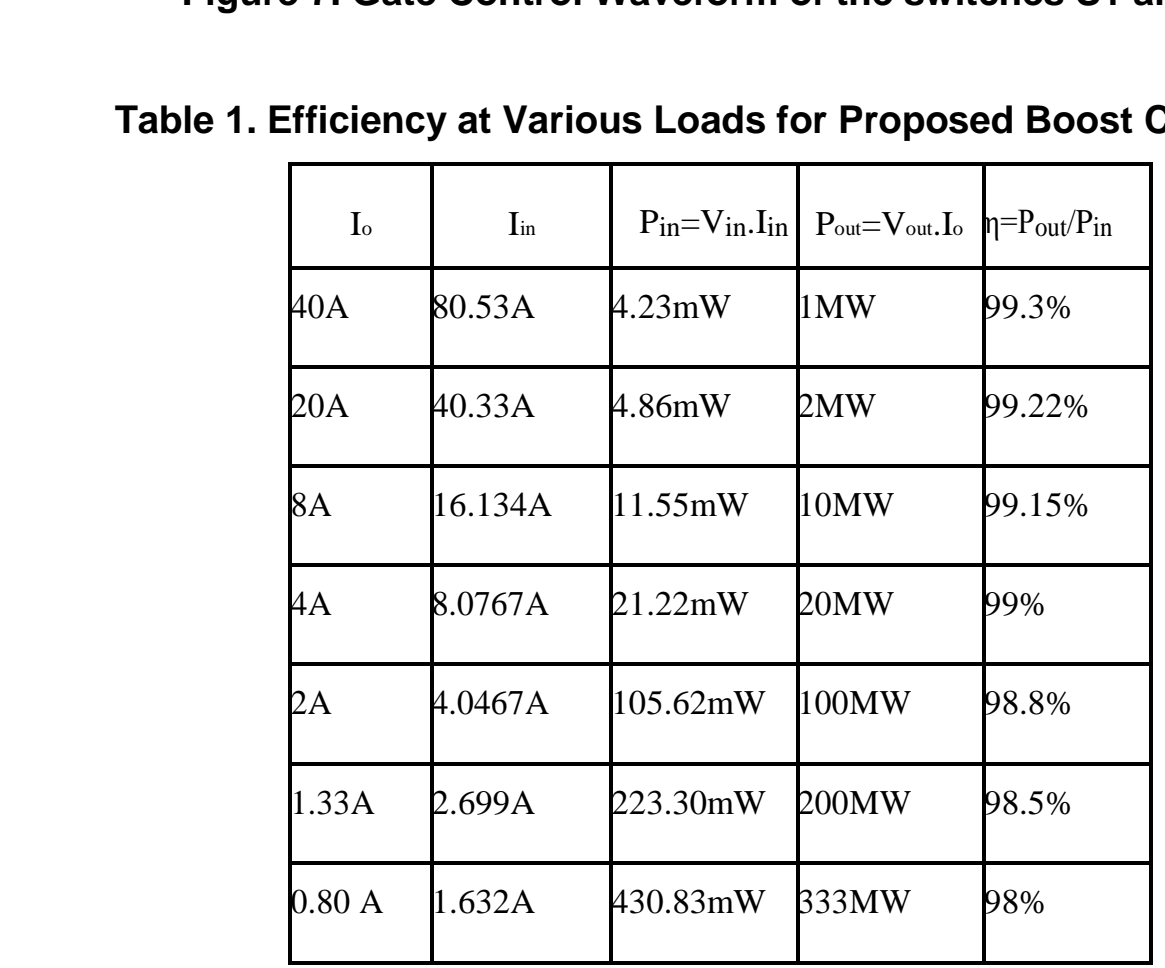


Table III gives value of efficiency for the proposed convertor at various loads. From Figure (8), it is seen that the overall efficiency of the new converter reaches a value of $99.3 \%$. It must be noted that this efficiency is greater than the converter presented in [11] although the circuit operates at similar frequency (100 KHZ). It is also worthwhile to mention that the efficiencies at low output powers of the proposed converter are relatively higher than most of the other soft switching converters.

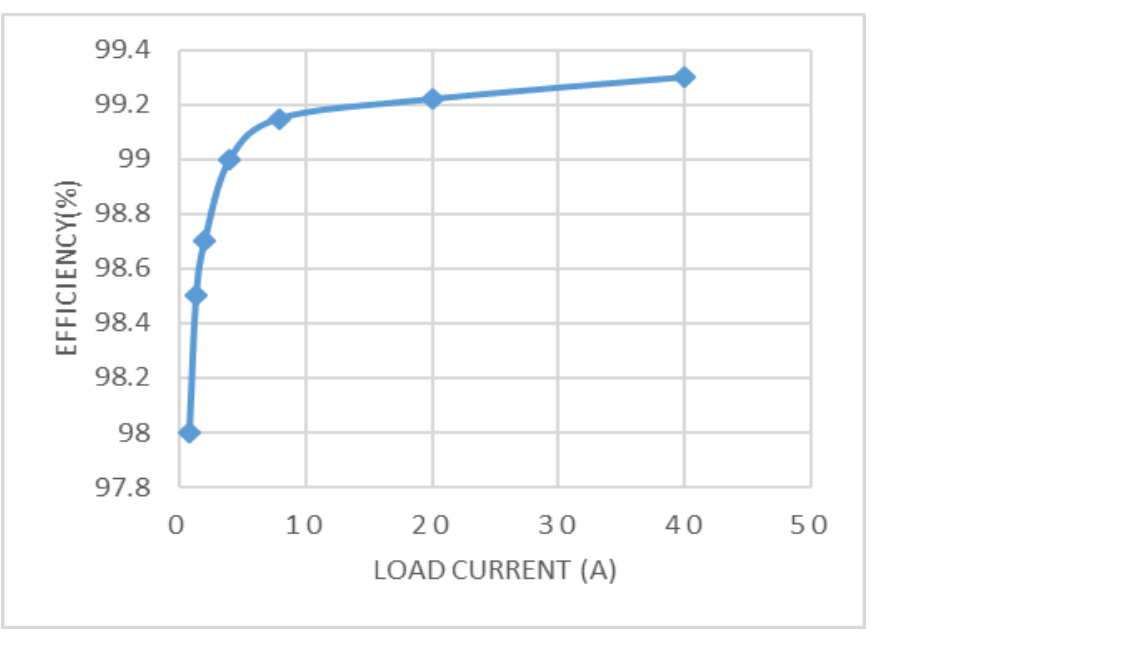

Figure 8. Plot between Load Current (A) and Efficiency of Boost Converter

In Figure 9 is shown the plot between the efficiency $(\%)$ and the output power (\%) for the ZVT ZCT Boost Converter [11] and the proposed boost converter. It is clear from the above plot that the efficiency of the proposed boost converter is higher than the ZVT ZCT Boost Converter [11] both at heaveds well as light loads. This proves that our proposed converter design is better as theffers high effieiency performance over a wide load range.

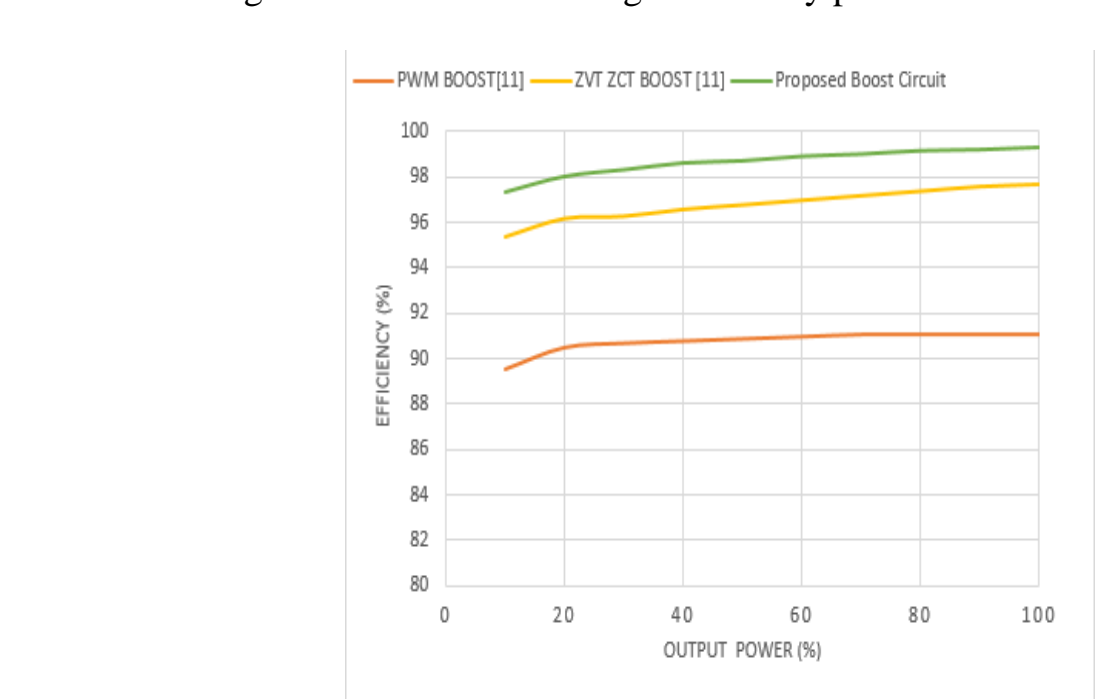

Figure 9. Efficiency of Proposed Boost Converter, ZVT-ZCT Converter and PWM Boost Converter

\section{Conclusion}

In this paper, a Novel Boost convertor which steps up the input voltage to $400 \mathrm{~V}$ output voltage was designed in PSIM software with a switching frequency of $100 \mathrm{KHz}$. The simulation results show that the proposed convertor has better efficiency than the conventional convertor over a wide load range. The features of the proposed Boost 
converter could be summarized as:

- Both the main and the auxiliary switch operate under soft switching conditions.

- $\quad$ All the semiconductor devices are not subjected to any additional voltage stress.

- $\quad$ Soft switching conditions are maintained for wide load range.

- The switching frequency of the proposed converter is constant.

However, in the proposed converter the compromise that is made is the addition of few components such as an auxiliary diode, and a zero-current detector. The compromise on additional components however results in the tremendous increase in efficiency. At a nominal output power, the efficiency of the proposed converter reaches approximately to a value of $99.3 \%$.

\section{References}

[1] G. Hua, C.-S. Leu, Y. Jiang and F. C. Y. Lee, "Novel zero-voltage-transition PWM converters" in IEEE Transactions on Power Electronics J. Clerk, vol. 9, no. 2, (1994), pp 213-219. Maxwell, A Treatise on Electricity and Magnetism, 3rd ed., vol. 2. Oxford: Clarendon, 1892 pp.68-73.

[2] G. Hua, E.X. Yang, Y. Jiang and F.C. Lee, "Novel zero-current-transition PWM converters", in Power Electronics, IEEE Transactions on , vol.9, no.6, (1994), pp.601-606.

[3] H.-S. Choi and B.H. Cho, "Novel zero-current-switching (ZCS PWM switch cell nûnimizing additional conduction loss", in Power Electronics Specialists Conference, 2001. PESC. 2001 IEEE 32nd Annual, vol.2, no., (2001), pp.872-877 vol.2.

[4] Taufik, P. Luther and M. Anwari, "Digitally controlled ZVS quasi-resonantboost converter with M-type switch", in Intelligent and Advanced Systems, 2007.ICLAS 2007. International Conference on , vol., no. , (2007), pp.823-828.

[5] O. Abdel-Rahim, M. Orabi, E. Abdelkarim, M. A hmed and M.Z. Youssef, "Switched inductor boost converter for PV applications", in Applied Power Electronic S Conference and Exposition (APEC), 2012 Twenty-Seventh Annual IEEE, vol., no (2012), pp.2100-2106.

[6] S.S. Saha, B. Majumdar, T. Halder and S.K. Biswas, New Fully Soft-Switched Boost-Converter with Reduced Conduction Losses", ir Power Electronics and Drives Systems, 2005. PEDS 2005. International Conference on , vol.1, no (2005), pp.107-112, 0-0 0

[7] T. Soong and P. Lehn, "A transformerless high boost DC-DC converter for use in medium / high voltage applications", in IECON 2012 - 38th Annual Conference on IEEE Industrial Electronics Society, vol., no. ,(2012), pp.174-179.

[8] H. Bodur and A.F. Bakan "A new ZVT-PWM DC-DC converter", in Power Electronics, IEEE Transactions on , vol 7 , no.1, (2002), pp.40-47.

[9] H. Bodur and A.F. Bakan, "A new ZVT-ZCT-PWM DC-DC converter", in Power Electronics, IEEE Transactions on vol 19, no.3, (2004) pp, 676-684.

[10] I. Aksoy H. Bodur and A.F. Bakan, "A New ZVT-ZCT-PWM DC-DC Converter", in Power Electronics, IFEE Transactioans on, vol.25, no.8, (2010), pp.2093-2105.

[11] N. Altintas, A.F. Bakan and I. Aksoy, "A Novel ZVT-ZCT-PWM Boost Converter", in Power Electronics, IEEE Tran sactions on , vol.29, no.1, (2014), pp.256-265.

[12] Venable Instruments, "Optimum Feedback Amplifier Design For Control Systems”, [Online]. Available: http://www.venable.biz/tp-03.pdf.

[13] N. Mohan, T.M. Undeland and W. P. Robbins, "Power Electronics: Converters, Applications, and Design", 3rd-Edition, Wiley, (2003).

[14] C. M. Chacko and S. P. Sathiyan, "Soft switched auxiliary resonant circuit based boost converter with reduced stress using ZVT PWM", Electrical, Computer and Communication Technologies (ICECCT), 2015 IEE E International Conference on, Coimbatore, (2015), pp. 1-5.

[15] B. Bryant and M. K. Kazimierczuk, "Modeling the closed-current loop of PWM boost DC-DC onverters operating in CCM with peak current-mode control", in IEEE Transactions on Circuits and Systems I: Regular Papers, vol. 52, no. 11, (2005), pp. 2404-2412.

[16] Jexas Instruments, "Practical Feedback Loop Analysis for Voltage Mode Boost Converter", [Online]. Available: http://www.ti.com/lit/an/slva633/slva633.pdf.

[17] M. H. Rashid, "Power Electronics: Circuits, Devices and Applications", $3^{\text {rd }}$ Edition,Prentice Hall, (2003). 


\section{Authors}

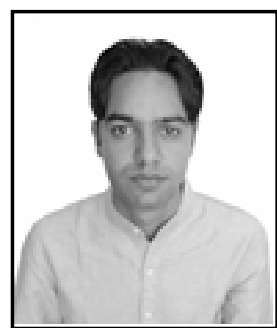

Furqan Zahoor, he was born in Srinagar, Jammu and Kashmir, India in 1990. He received the $B$. Tech degree in electronics and communication engineering from University of Kashmir, Srinagar, India in 2014 and $\mathrm{M}$. Tech degree in electronics and communication engineering from Shri Mata Vaishno Devi University, Katra, India in 2016. His research interests include efficiency improvement of Boost converters, switching power supplies, snubber cells in power electronics.

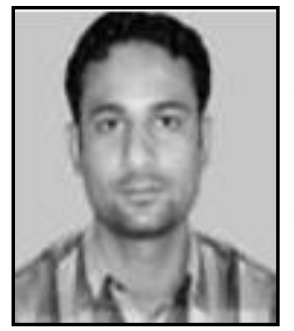

Swastik Gupta, he was born in Jammu, Jammu and Kashmir, India. $\mathrm{He}$ received the B. Tech degree in Electrical Engineering from, University of Jammu in 2010 and M. tech degree in electronics and communication engineering from Indian Institute of Technology (IIT), Kanpur, India in 2014.His research interests include Emb dded Systems, Virtual Instrumentation, Distributed Control Systems

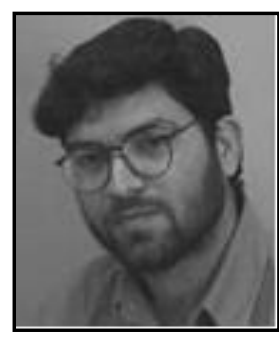

Vipan Kakkar, he was born in Amritsar, India, in 1973. He received the B.E, degree in electronics and communication engineering from Nagppur University, India, in 1994 and M.Sc. degree from Bradford University, UK in 997. He received his Ph.D. degree in electronics and communication engineering from Delft University of Technology Nletherlands in 2002.

$\mathrm{He}$ worked in Research \& Development at Phillips, Netherlands as engneer and system architect from 2001 to 2009. Since 2009, he has been an Associate Professor with the - Department of Electronics and Communication Engineering, Shri Mata Vaismno Devi University, Katra, India. His research interests include ultra low power analog and mixed signal design, MEMS design, synthesis and optimization of digital circuits, biomedical system and implants design, audio and video processing.

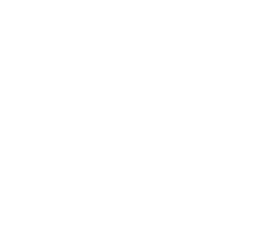


International Journal of Hybrid Information Technology

Vol. 9, No.11 (2016)

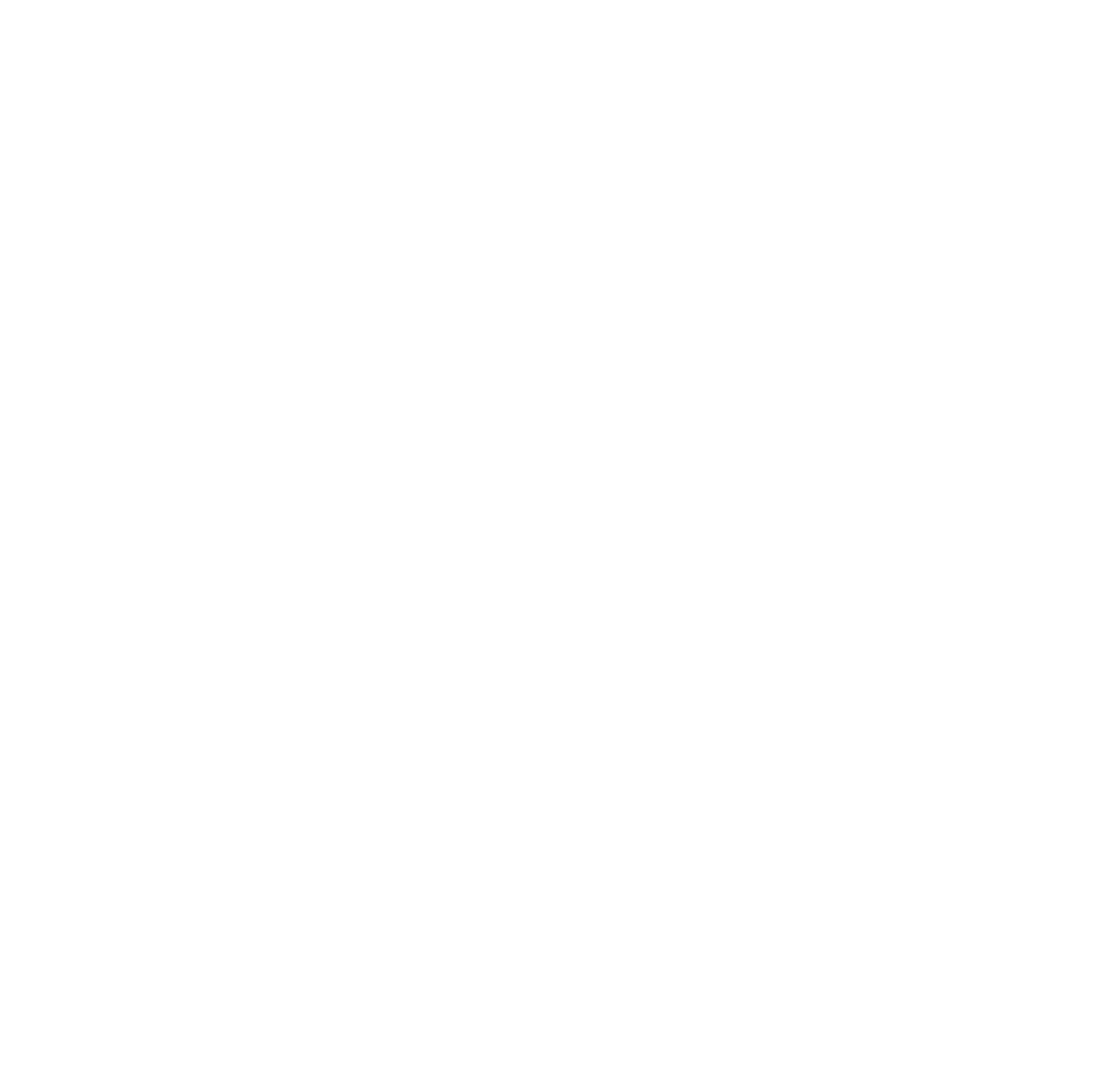

